\title{
Epidemiology of urolithiasis in dogs from Guadalajara City, Mexico
}

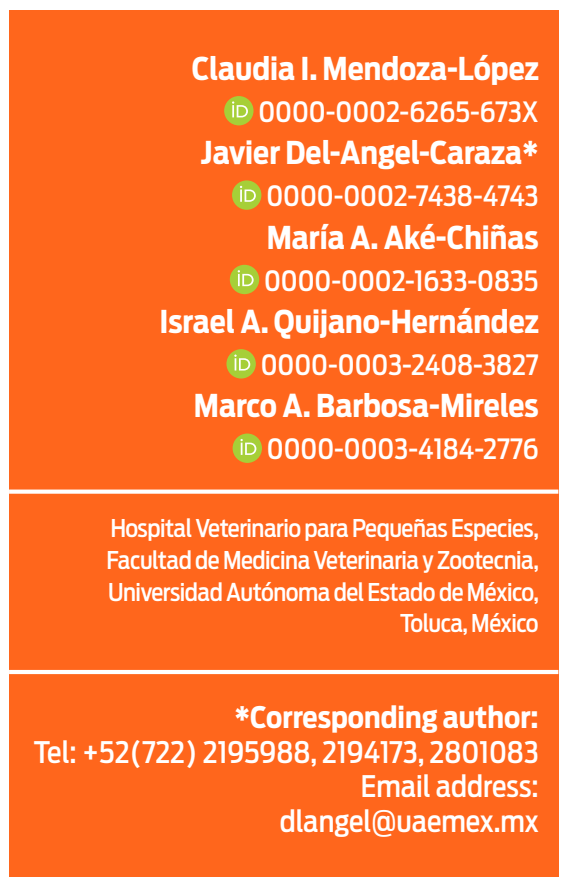

Accepted: $2018-09-25$

Published: 2019-03-22

Additional information and declarations can be found on page 12

@Copyright 2019
Claudia I Mendoza-López etal. open access $\boldsymbol{\varnothing}$

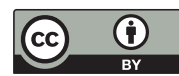

Distributed under Creative Commons CC-BY 4.0

\begin{abstract}
Urolithiasis is a frequent and recurrent problem in dogs around the world. Several epidemiological studies based on mineral composition of uroliths have been carried out in different geographical areas. The objective of this study was to analyze epidemiological data of 195 dogs with urolithiasis from the metropolitan area of Guadalajara Jalisco, Mexico. To determine the chemical composition of uroliths, quantitative and qualitative analyses were performed by means of stereoscopic microscopy and infrared spectroscopy. The dogs' median age was six years and a male-female ratio of 1.4:1 was observed. The most affected pure breed dogs were schnauzer, poodle, Labrador retriever, Yorkshire terrier, and German shepherd. The frequency of uroliths of struvite, calcium oxalate, urates, mixes, and compounds, is similar to the one found in other studies performed in other populations. However, a much higher frequency of silicate-containing uroliths (16.92\%) was observed, both in a pure form as well as in mineral mixtures. These results led us to suggest the need to develop further investigations to determine the origin of this high frequency.
\end{abstract}

Keywords: urolithiasis, epidemiology, risk factors, dogs, Mexico

\section{Cite this as:}

Mendoza-López Cl, Del-Angel-Caraza J, Aké-Chiñas MA, Quijano-Hernández IA, Barbosa-Mireles MA. Epidemiology of urolithiasis in dogs from Guadalajara City, Mexico. Veterinaria México OA. 2019;6(1). doi: 10.22201/fmvz.24486760e.2019.1.585. 
In memory of Dr. Carl Osborne (1940-2017), whose example motivated many of us to study urinary diseases in dogs and cats.

\section{Introduction}

Urolithiasis is a frequent and recurrent problem in dogs around the world. It accounts for $18 \%$ to $20.61 \%$ of dogs with lower urinary tract diseases referred to veterinary hospitals in the USA and Mexico. ${ }^{1,2}$ The mortality rate is between 0.5\% and 3\% in veterinary hospitals in the US and Germany. ${ }^{1}$ The prevalence has only been determined in Norway and Sweden, at $0.05 \%$ and $0.24 \%$ respectively. ${ }^{3}$

Urolithiasis is a multifactorial disease with implied epidemiological aspects influenced by different risk factors. These include breed, sex, age, diet, anatomical and functional urinary alterations, metabolic disorders, genetic predisposition, and bacterial urinary tract infection (BUTI), ${ }^{4}$ as well as factors inherent to the geographic area. ${ }^{2,5}$

Patients with urinary stones generally present clinical signs such as pollakiuria, hematuria, and strangury; diagnosis is confirmed by radiography and ultrasonography. Uroliths should be eliminated from the urinary tract, if possible, with non-invasive procedures such as the dissolution of uroliths using therapeutic diets. It can also be achieved through a minimally invasive procedure such as bladder voiding through urohydropropulsion, or percutaneous cystolithotomy; or invasively with conventional cystotomy. ${ }^{6}$

An animal that formed uroliths will likely form them again. Therefore, it is necessary to find a preventing therapeutic measure, even if uroliths have already been removed. In the long term, the effective management of this disease depends on the identification and control of pathophysiological mechanisms involved in forming uroliths. These depend on the precise mineral composition: struvite, calcium oxalate ( $\mathrm{CaOx})$, purines, silica, calcium phosphate, cystine, or a mixture of these. ${ }^{6}$

It is difficult to determine the mineral composition of a urolith based only on physical characteristics such as form, size, color, and number (Figure 1). The composition analysis has to be performed in a reference laboratory, combining different methods such as stereoscopic microscopy, Rx diffraction, infrared spectroscopy, or other quantitative methods. ${ }^{4}$

Different layers form the structure of a urolith: the nucleus or nidus in the centre, which begins the formation of a urolith and may have a mineral origin, a protein matrix, or foreign bodies such as a suture; the stone or calculus which has multiple laminations that give body or volume to the urolith; and the shell, which is the last complete layer. The surface crystals comprise the outermost and incomplete layer (Figure 2). Each layer has a mineral composition which may be similar to or different from the others. ${ }^{4}$

Based on the mineral composition of uroliths, epidemiological studies in dogs and cats have been carried out in different geographical areas. In an analysis of studies performed in the American continent (Canada, ${ }^{7}$ USA, ${ }^{8}$ Venezuela, ${ }^{9}$ Brazil, $^{10}$ and Mexico $)^{11}$ it was described that struvite and $\mathrm{CaOx}$ uroliths account for more than $73 \%$ of cases; the rest were formed of purines, silica, cystine, calcium phosphate, and mixtures in different proportions. In Mexico City, a high frequency 


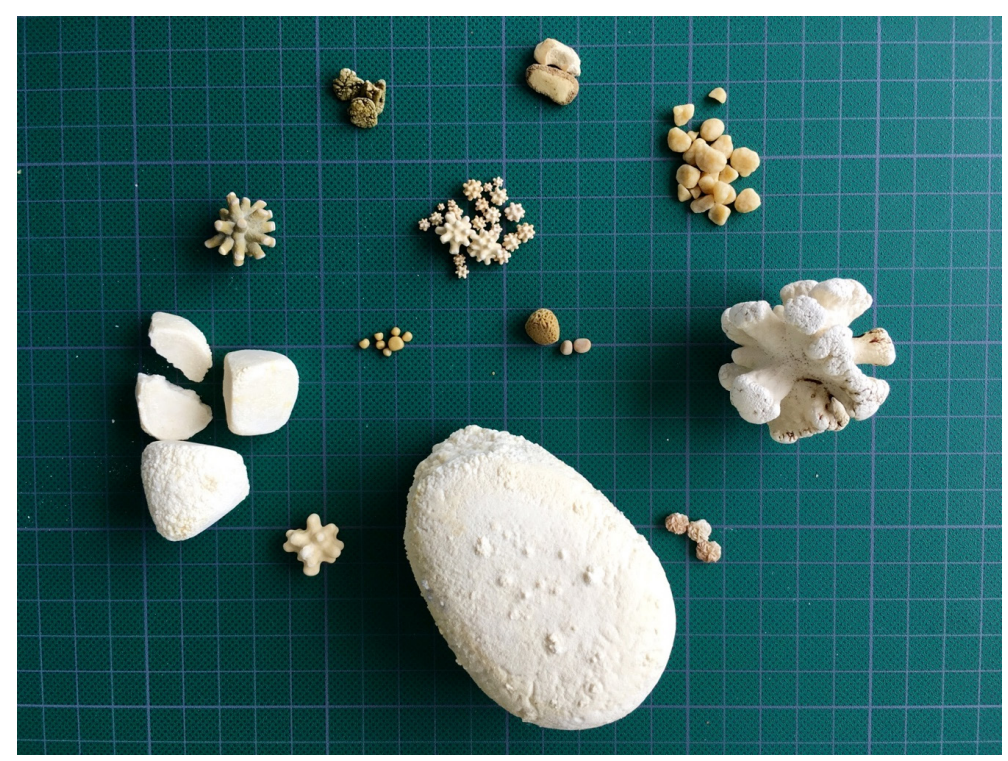

Figure 1. Different types of uroliths. Note the differences in shape, size, color, and number; however, none of these characteristics is specific to a particular mineral composition.

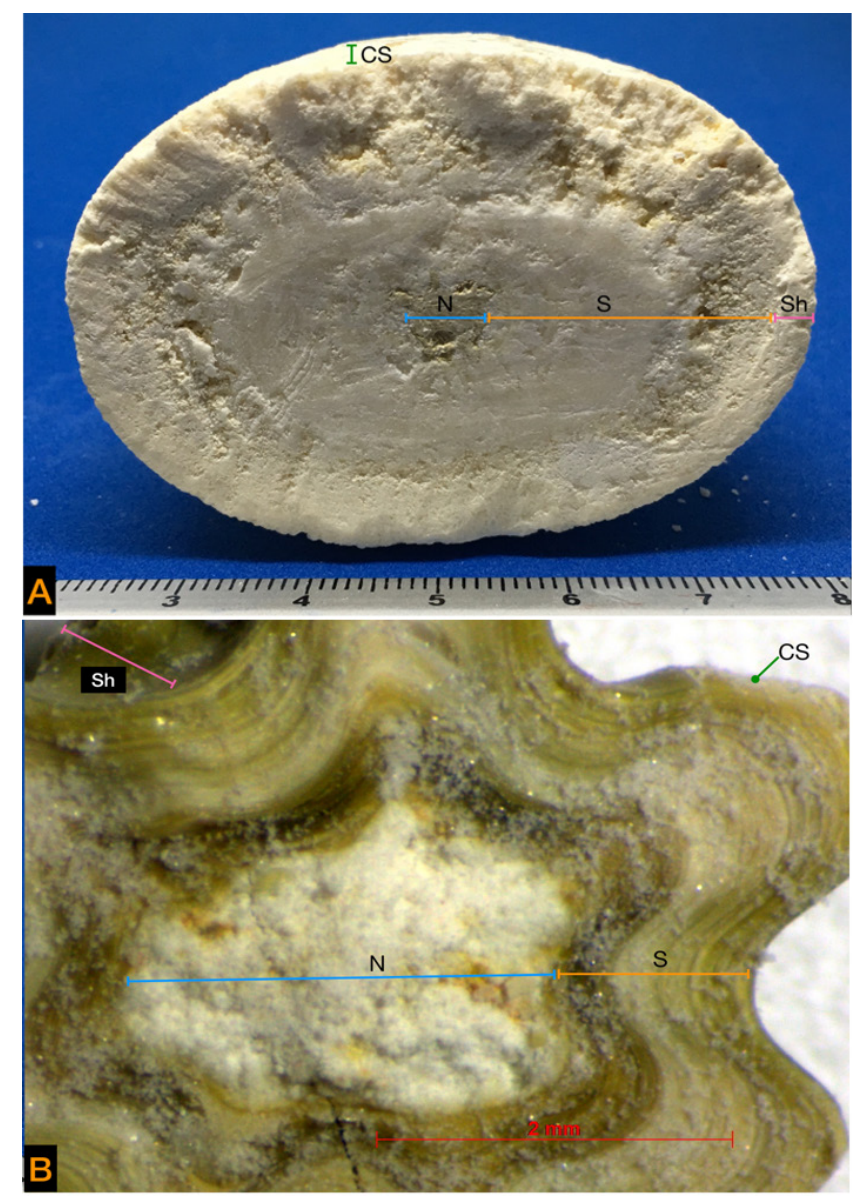

Figure 2. Internal structure of a urolith. N: nucleus or nidus, S: stone; Sh: shell; CS: crystals surface. A) Struvite urolith. B) Compound urolith: struvite nucleus, silica stone and shell, and struvite crystal surface (AxioCam ERc5s and Stemi DV4 Stereo-Microscope, Zeiss, USA). 
of silicate uroliths (14\%) has been evidenced, ${ }^{11}$ which contrasts the $1 \%$ maximum reported in the studies mentioned before.

The purpose of this study was to analyze epidemiological data of urolithiasis in dogs from the metropolitan area of Guadalajara, Jalisco. This city acquires a special relevance because it is the second most populated in Mexico.

\section{Materials and methods}

\section{Study area}

The metropolitan area of Guadalajara is in the west of Mexico, in the central region of the state of Jalisco. It has a territorial extension of $187.91 \mathrm{~km}$. It is situated in the Atemajac valley, in the neovolcanic axis, established at an altitude of 1536 meters above sea level. ${ }^{12}$

\section{Sample collection}

From 2006 to 2016, canine uroliths were collected from different veterinary clinics located in the metropolitan area of Guadalajara, Jalisco, Mexico. The following data were analyzed: age, sex, race, and the anatomic location where the uroliths were found, as well as their mineral composition. Dogs were classified in four age groups: younger than 1 year, from 1 to 4 years, 5 to 8 years, and 9 to 14 years. Only pure breeds were classified according to size: small size $(<10 \mathrm{~kg})$ and large size (> $10 \mathrm{~kg})$.

\section{Analyses and classification of uroliths}

To determine their chemical composition, uroliths were submitted for qualitative and quantitative analyses, which were carried out in the National Reference Laboratory for the Analyses of Animal Uroliths of the Hospital Veterinario para Pequeñas Especies de la Facultad de Medicina Veterinaria y Zootecnia de la Universidad Autónoma del Estado de México, Toluca, Mexico. The appearance and characteristics of the external surface were evaluated by direct inspection or by stereoscopic microscopy (Figure 2) (Stemi DV4 Stereo-Microscope, Zeiss, USA). Uroliths with a diameter $>5 \mathrm{~mm}$ were cut in half to observe the internal architecture, in order to differentiate their layers. The chemical composition of each of the urolith layers was analyzed by infrared spectroscopy (FT-IR Spectrum two, Perkin Elmer, USA). In the case of uroliths $<5 \mathrm{~mm}$, they were crushed and analyzed as a single layer. Uroliths were classified as simple or pure when they were formed of one layer or the different layers had a similar composition, with more than $70 \%$ of a mineral (80\% struvite and $20 \% \mathrm{CaOx}$, or $100 \%$ struvite); as mixtures when formed by a combination of minerals with less than $70 \%$ of a specific mineral (50\% struvite and $50 \% \mathrm{CaOx}$ ); or as compounds when the urolith had layers of different composition (struvite nucleus, mixed struvite stone with $\mathrm{CaOx}$ and struvite bark), as described by Osborne et al. ${ }^{4}$ The qualitative interpretation of the obtained spectra was based on those described by Hidalgo. ${ }^{13}$ For the quantitative analysis of the following minerals: struvite, $\mathrm{CaOx}$, calcium phosphate, cystine, purines, and mixtures, an electronic library of reference spectra (Nicodom IR Kidney stones 1668 spectra, Nikodom of 
the Czech Republic) was used, and for uroliths of silicate and its mixtures with other minerals, a library was developed in our laboratory. ${ }^{14}$ In this study, the term "calcium oxalate" (CaOx) includes mono-hydrated forms, di-hydrated forms, or mixtures thereof; the term purines includes ammonium urate, sodium urate, and uric acid.

\section{Data analysis}

Statistical analyses were performed on GraphPad prism 6.0, using $\chi^{2}$, determination of odds ratio (OR), and 95\% confidence interval $(95 \% \mathrm{Cl})$. Differences were considered significant when $\mathrm{p}<0.05$.

\section{Results and discussion}

The uroliths of 195 dogs were analyzed: $58.46 \%(n=114)$ of these came from males, with a male-female ratio of 1.4:1.

Dogs had a median age of six years, with a range between 2 months and 14 years. The highest frequency of uroliths (60.51\%) was observed in dogs between five and eight years old.

Twenty-eight pure breeds were identified in the studied sample, representing $84.10 \%(n=164)$ of the total, the rest were crossbreed dogs. The most frequent breeds were schnauzer, poodle, Labrador retriever, Yorkshire terrier, and German shepherd.

Pure breed animals $(n=164)$ were classified based on their size: $72.56 \%$ $(n=119)$ were small-size and 27.44\% $(n=45)$ large-size.

As for the anatomical location of uroliths, most (74.87\%) were in the bladder $(n=146) ; 12.30 \%$ in urethra $(n=24) ; 9.20 \%$ both in bladder and urethra at the same time $(n=18) ; 3.07 \%$ in kidneys $(n=6)$; and $0.51 \%$ in kidneys and bladder simultaneously $(n=1)$.

The most frequent type of urolith (44.10\%) was struvite $(n=86)$, followed by $29.74 \% \mathrm{CaOx}(n=58), 9.23 \%$ silica $(n=18), 7.17 \%$ purines $(n=14), 1.02 \%$ calcium phosphate $(n=2), 5.64 \%$ mixed uroliths $(n=11)$, and $3.07 \%$ compound uroliths $(n=6)$. The frequency of different types of urolith in relation to gender and age group is shown in Table 1, the risk analysis of predisposition of gender to present some type of urolithiasis in Table 2 , and the association between urolith type and breed size in Table 3.

Struvite uroliths were the most frequent with $44.10 \%(n=86)$ of the sample; females were more frequently affected with $60.46 \%(n=52)$ and a significant association was found to form this type of urolith $(p<0.001)$, with a female-male ratio of 1.5:1. Similarly, struvite uroliths were more frequent (54.65\%) in the five to eight years old group ( $n=47)$; however, dogs between 9 and 14 years old presented a significantly higher risk $(p<0.01)$. This type of urolith was the only one that was present in puppies. Pure breed dogs comprised 70.93\% $(n=61)$ of the studied sample, the rest being crossbreed animals which presented a significant risk $(p<0.001)$. The most affected breeds were schnauzer $(31.14 \%)$, poodle (12.79\%), and cocker spaniel (8.19\%). On the basis of size, small sized animals were the most affected, $83.60 \%(n=51)$, with a significant risk $(p<0.01)$. Small sized female dogs, particularly schnauzer, poodle, and cocker spaniel 
Table 1. Frequency of different types of urolith according to gender and age group.

\begin{tabular}{|c|c|c|c|c|c|c|c|}
\hline \multirow{2}{*}{ Type of urolith } & \multirow{2}{*}{$\begin{array}{c}\text { Frequency } \\
n(\%)\end{array}$} & \multirow{2}{*}{$\begin{array}{l}\text { Female } \\
n(\%)\end{array}$} & \multirow{2}{*}{$\begin{array}{l}\text { Male } \\
n(\%)\end{array}$} & \multicolumn{4}{|c|}{ Age group in years, $n(\%)$} \\
\hline & & & & $<1$ & $1-4$ & $5-8$ & $9-14$ \\
\hline Struvite & $86(44.10)$ & $52(60.46)$ & $34(39.54)$ & $6(6.9)$ & $13(15.11)$ & $47(54.56)$ & $20(23.25)$ \\
\hline $\mathrm{CaOx}$ & $58(29.74)$ & $16(27.58)$ & $42(72.41)$ & 0 & $5(8.62)$ & $43(74.13)$ & $10(17.24)$ \\
\hline Silica & $18(9.23)$ & $1(5.6)$ & $17(94.44)$ & 0 & $5(27.77)$ & $8(44.44)$ & $5(27.77)$ \\
\hline Purins & $14(7.1)$ & $5(35.71)$ & $9(64.28)$ & 0 & $3(21.42)$ & $11(78.57)$ & 0 \\
\hline Mixed & $11(5.64)$ & $5(45.45)$ & $6(54.54)$ & 0 & $3(27.27)$ & $8(72.72)$ & 0 \\
\hline Compounds & $6(3.07)$ & $1(16.67)$ & $5(83.33)$ & 0 & $3(50)$ & $3(50)$ & 0 \\
\hline Others & $2(1.02)$ & $1(50)$ & $1(50)$ & 0 & 0 & $2(100)$ & 0 \\
\hline Total & $195(100)$ & $81(41.5)$ & $114(58.5)$ & $6(3.07)$ & $32(16.41)$ & $122(62.56)$ & $35(17.94)$ \\
\hline
\end{tabular}

Table 2. Gender predisposition to present some type of urolithiasis.

\begin{tabular}{|l|l|l|l|l|}
\hline \multicolumn{1}{|c|}{ Type urolith } & Gender $\mathbf{n}(\mathbf{\%})$ & OR & IC 95\% & P \\
\hline Struvite & $\mathrm{F}=52(60.46)$ & 4.219 & $2.318-7.676$ & $\mathbf{0 . 0 0 0 1}$ \\
\hline \multirow{2}{*}{$\mathrm{CaOx}$} & $\mathrm{M}=34(39.54)$ & 0.237 & $0.130-0.431$ & 0.0001 \\
\hline \multirow{2}{*}{ Silica } & $\mathrm{F}=16(27.58)$ & 0.422 & $0.224-0.807$ & 0.010 \\
& $\mathrm{M}=42(72.41)$ & 2.37 & $1.238-4.451$ & $\mathbf{0 . 0 1 0}$ \\
\hline Purines & $\mathrm{F}=1(5.6)$ & 0.071 & $0.006-0.430$ & 0.001 \\
\hline \multirow{2}{*}{ Others } & $\mathrm{M}=17(94.44)$ & 14.02 & $2.322-149$ & $\mathbf{0 . 0 0 1}$ \\
\hline & $\mathrm{F}=5(35.71)$ & 0.767 & $0.279-2.323$ & 0.646 \\
\hline
\end{tabular}

F: Female; M: Male; Others: mixed, compounds

Table 3. Association between urolith type and breed size $(n=164)$.

\begin{tabular}{|l|c|c|c|c|}
\hline Type of urolith & Breed Size & OR & Cl 95\% & P \\
\hline Struvite & $\mathrm{S}=51$ & 2.625 & $1.181-5.6$ & $\mathbf{0 . 0 1 4}$ \\
\hline CaOx & $\mathrm{L}=10$ & 0.381 & $0.178-0.846$ & 0.014 \\
\hline \multirow{2}{*}{ Silica } & $\mathrm{S}=46$ & 1.948 & $0.893-4.229$ & 0.088 \\
& $\mathrm{~L}=11$ & 0.513 & $0.236-1.119$ & 0.088 \\
\hline Purins & $\mathrm{S}=3$ & 0.057 & $0.017-0.191$ & $<0.0001$ \\
\hline \multirow{2}{*}{ Others } & $\mathrm{L}=14$ & 17.46 & $5.22-58.74$ & $<\mathbf{0 . 0 0 0 1}$ \\
\hline & $\mathrm{S}=8$ & 0.738 & $0.2377-2.308$ & 0.889 \\
\hline
\end{tabular}

S: Small size breeds; L: Large size breeds; Others: mixed, compounds. 
dogs aged 9 to 14 years, were at a higher risk of presenting struvite urolithiasis $(p<0.021)$.

Calcium oxalate urolithiasis was present in $29.74 \%(n=58)$ of the cases, and was the second most frequent type; $72.41 \%(n=42)$ of this urolith came from males, showing a higher risk of forming this type of urolith $(p<0.01)$, with a male-female ratio of 2.6:1. It occurred more frequently (74.13\%) in 5 to 8 years old dogs $(n=43) ; 98.27 \%(n=57)$ were found in pure breed dogs, which had a significant risk $(p<0.001)$. The schnauzer was the most predisposed breed with $47.36 \%(n=27)$ of cases, with a high predisposition $(p<0.001)$. Small breeds were the most affected, $80.70 \%(n=46)$.

Silica uroliths represented 9.23\% $(n=18)$ of cases, being the third most common type of uroliths in the population. Of these cases, $94.44 \%(n=17)$ were male $(p<0.001)$ and were more frequently present in the age group of five to eight years with $44.44 \%(n=8)$. In this group, $94.44 \%(n=17)$ were pure breeds and the Labrador retriever was the most frequently affected breed. Large animals comprised $82.35 \%(n=14)$ of cases $(p<0.0001)$. In the population studied, it was found that pure breed, large sized male dogs had a higher risk of forming this type of uroliths $(p<0.01)$.

Purine uroliths were found in 7.17\% $(n=14)$ of cases; $64.28 \%(n=9)$ were males, with a male-female ratio of 1.8:1. Of the cases, $78.57 \%(n=11)$ occurred in the age group of five to eight years. In pure breed dogs, these uroliths were present in $85.71 \%(n=12)$ of cases, Dalmatians and schnauzers being the breeds most frequently affected (33.3\% each). Statistically, male Dalmatians presented a high risk of forming purine urolithiasis $(p<0.0001)$.

Mixed uroliths were found in $5.6 \%(n=11)$ of cases, five of which were struvite, silica, and calcium phosphate mixtures, in different rates: four $\mathrm{CaOx}$ and silica mixtures, and two of struvite with $\mathrm{CaOx}$. Of these cases, 54.54\% $(n=6)$ were found in males, with a male-female ratio of 1.2:1. Animals between five and eight years old comprised $72.72 \%(n=8)$ of cases, and 90.90\% $(n=10)$ were present in pure breeds such as Yorkshire terrier, schnauzer, German shepherd, Labrador retriever, Scottish terrier, Dalmatian, and springer spaniel, representing 60\% $(n=6)$ of the small size breeds .

Compound uroliths were found only in six cases, all with a silicate nucleus of $\mathrm{CaOx}$ stones, struvite, or mixtures of these minerals with silica. Five of the cases were males with an age range from one to six years. These uroliths were present in only three breeds: schnauzer, Labrador retriever and poodle.

Only two cases of calcium phosphate urolithiasis were found, one of brushite in a female poodle, and one of carbapatite in a male poodle, both five years old.

Urolithiasis is a chronic and common disease that affects different species such as dogs and cats. It is a multifactorial disease, which can present lower urinary tract clinical signs. To determine the mineral composition of uroliths, performing a microscopic evaluation of the crystals in the urinary sediment will only give an idea of the possible composition of the urolith, and is generally related only to the most superficial layer of the urolith. Based on radiographic and visual evidence, as well as findings revealed by urinalysis, one can try to predict the mineral composition of the urolith and to consider dissolving struvite uroliths. Since this therapeutic alternative is not possible, it is necessary to extract them from the urinary tract using minimally invasive techniques whenever possible, in order to send them to a reference lab- 
oratory to be analyzed and consequently decide the best therapeutic strategy to avoid their recurrence in the long term.

In the studied population, males are slightly more affected with urolithiasis, comprising $58.46 \%$ of cases. It is more common for uroliths to be retained in the male urinary tract, since they have a longer and narrower urethra that makes it difficult for the urolith to be naturally expelled, unlike females, who can, in some cases, expel small uroliths because of their shorter and looser urethra. ${ }^{2}$

Urolithiasis can occur at any age, from puppies to geriatric animals. The studied population presented a median age of six years. Animals between five and eight years old are considered at greater risk. Perhaps in this age group, animals can commonly present systemic or metabolic diseases, including urinary tract alterations that can cause changes in its defense mechanisms and thus favor the presentation of urolithiasis. In puppies, only struvite uroliths were found, suggesting BUTI is associated with anatomical alterations or congenital diseases. ${ }^{15}$

Regarding breed, no predisposition was evidenced, since 28 different breeds were identified in addition to crossbreed dogs. According to size, the most affected small breeds were schnauzer, poodle, and Yorkshire terrier; whereas in the large breeds, the Labrador retriever and the German shepherd breeds were more susceptible. The above-mentioned breeds are popular breeds in Mexico, and they are also frequently reported as urolithiasis patients in Mexico City. ${ }^{11}$

Anatomically, uroliths were found in the urinary tract in $97 \%$ of cases, as has been reported in other studies. ${ }^{16,17}$ Nephrolithiasis represented only 3\% of the cases, similar to that reported by Ling, ${ }^{18}$ who describes it with a frequency of less than $4 \%$.

Based on mineral composition, the most frequently presented uroliths were those of struvite, accounting for $44.10 \%$, followed by $\mathrm{CaOx}(29.74 \%)$, silica $(9.23 \%)$, and purines $(7.17 \%)$. These data are similar to a previous study in Mexico City, ${ }^{11}$ where it was observed that these minerals are the most frequent and were present in almost the same rates. However, this is different from what is reported in other geographical areas.

In cases of struvite and $\mathrm{CaOx}$ urolithiasis, differences have been published concerning the frequency of these uroliths, as studies in Brazil, ${ }_{1}^{10}$ United Kingdom, 1,9 and Hungary 20 report struvite urolithiasis as the most frequent. In other geographical areas such as Spain and Portugal, ${ }^{21}$ France, ${ }^{16}$ and Switzerland, ${ }^{22} \mathrm{CaOx}$ is reported to be the most common mineral of uroliths. These changes are possibly related to demographic factors, breed preferences, changes in the composition of commercial diets, and the possibility of dissolving struvite uroliths.

In different studies, females had a higher risk of presenting struvite urolithiasis possibly due to a greater predisposition to BUTI related to the anatomical differences of the urethra. ${ }^{23,24}$ To form struvite uroliths, supersaturation in the urine with phosphate, ammonium, and magnesium is required. Most of these uroliths are associated with a BUTI caused by urease-producing bacteria, the most common in dogs being Staphylococcus pseudintermedius and Proteus mirabilis; others occasionally producing urease are E. coli, Pseudomonas, and Klebsiella. ${ }^{25}$ Urease is an enzyme that hydrolyzes urea, increasing the concentration of ammonium and carbon dioxide, thus producing alkaline urine, which will favor struvite crystals to precipitate if phosphate and magnesium obtained from diet are present. The most frequent age of occurrence was between five and eight years; however, dogs in 
the age range between 9 to 14 years are proner to present this type of urolithiasis, related to the fact that advanced age dogs can present a BUTI secondary to neurological alterations of urination; or endocrine diseases like diabetes mellitus or hyperadrenocorticism, as well as prostatic diseases. ${ }^{2}$ Usually, the appearance of these uroliths in radiographic studies is radiopaque and they have diverse forms when they are multiple: they can present flat faces and acquire a pyramidal form. They are commonly found in alkaline urine, near a pH of 8 . These uroliths can be dissolved in a period of two to five weeks with the use of therapeutic diets. These diets generally decrease urinary supersaturation with phosphate, ammonium and magnesium, and promote acidic urine, inhibiting precipitation of crystals and thus dissolving uroliths. In addition, an adequate antibiotic therapy is required and should be maintained during the urolith dissolution process, since it is possible that bacteria are released from the urolith layers as they dissolve. ${ }^{26}$ It is important to perform periodic radiographic studies during the dissolution process, in order to observe and measure the size of uroliths to verify their decrease in size.

In the case of $\mathrm{CaOx}$ uroliths, the majority came from males. It has been suggested that in males there is a decreased urinary excretion of citrate, an inhibitor of urinary crystallization of $\mathrm{CaOx}$, which can promote crystallization and formation of this type of urolith. ${ }^{27}$ The pathophysiology of the formation of $\mathrm{CaOx}$ uroliths in dogs is not yet fully understood, but conditions that promote hypercalciuria and hyperoxaluria are known as predisposing factors. Hypercalciuria can occur for different reasons: excessive intestinal absorption of calcium; altered calcium resorption in the renal tubules, as in metabolic acidosis; primary or secondary hyperparathyroidism; paraneoplastic syndrome; or hyperadrenocorticism. Hyperoxaluria derives from intestinal hyperabsorption or the accelerated synthesis of oxalic acid. Recently, it has been suggested that in dogs, the reduction of Oxalobacter formigenes load in the gastrointestinal tract could predispose them to $\mathrm{CaOx}$ urolithiasis, considering this bacterium is part of the normal microbiota and degrades oxalate to obtain energy. ${ }^{28}$ Generally, this type of urolith is radiopaque, round or irregular in shape; multiple and smaller than $5 \mathrm{~mm}$, which allows its expulsion from the urinary tract in females. The urinary $\mathrm{pH}$ in which they are found is variable. It is worth mentioning that these uroliths cannot be dissolved and their extraction from the urinary tract is necessary, if possible, by means of minimally invasive techniques. ${ }^{6}$ Long-term management is essential to try to control recidivism.

Silicate uroliths were found in $9.23 \%$ of the cases studied. This type of urolithiasis has not been reported in epidemiological studies conducted in geographical areas such as France, ${ }^{16}$ Hungary, ${ }^{20}$ or Ireland; ${ }^{29}$ or they have been reported with a frequency of less than 1\%, as in Brazil, ${ }^{10}$ United Kingdom, ${ }^{19}$ Spain and Portugal, ${ }^{21}$ and Canada. ${ }^{30}$ Frequencies similar to those found in our study have been documented only in Switzerland (8\%) 22 and in a study of Mexico City, with a frequency of $14 \% .{ }^{11}$ The reasons for this finding may be related to a geographical factor. Silica is present not only in its pure form, but also in mixed uroliths, mixed other minerals such as struvite, calcium phosphate, and $\mathrm{CaOx}$, as well as in compound uroliths with a silica nucleus. Taking into account these data, we consider that uroliths containing silicate represent $16.92 \%$ of cases. This type of urolith may be in the form of a jackstone, with radial projections varying in number and size-some are long and thin while others are blunt and slightly apparent-or round, smooth shapes. They vary in size and can measure from a few millimeters to centimeters and, in 
most cases, they are multiple. Silicate is a combination of silicon, oxygen, and other elements. It is present in water and some foods of plant origin. The level of silica is influenced by diet and renal elimination depends on the amount consumed. It has been proposed that silicate urolithiasis develops due to increased ingestion of dietary solid components and/ or through the intake of water with a high content of silica, such as local groundwater near volcanoes. In Mexico, there is the Trans-Mexican eovolcanic axis, which is a chain of volcanoes that extends transversely from coast to coast, from the Pacific Ocean to the Gulf of Mexico. ${ }^{31}$ The state of Jalisco is located within this Trans-Mexican neovolcanic axis, so we suggest that there might be a relationship between the affected animals and their geographical location, since it is very likely that in Guadalajara city the groundwater contains high amounts of silica, similar to what is found in Mexico City, where its most important source of water comes from groundwater found in volcanic areas. ${ }^{11}$ However, future studies on the concentration of silicates in water will be necessary to verify this association. In our results, large sized and Labrador retriever dogs were the most affected. Similar data were reported in the population studied in Switzerland. ${ }^{22}$ The higher frequency in males can be associated with the urinary tract anatomy, since males have a narrower and longer urethra, while the females' urethra is shorter and lax, allowing a urolith to be more easily expelled. Based on size, large breeds have a greater urinary volume, which may favor a higher concentration of this mineral in urine. As part of the medical management, it is recommended to provide dogs with water low in silica, as well as high quality foods, since low quality dietary food acquires protein from products such as beet pulp or cereals that contain high levels of silica.

Purine uroliths were more likely to be present in Dalmatian males, which is consistent with several studies. 17,23,32 Purine uroliths include uric acid compounds, ammonium urate, and sodium urate. These uroliths are usually multiple, small, smooth, ovoid, and greenish. Uric acid is the product of degrading endogenous purines as well as the dietary ones. Purines are converted to hypoxanthine and xanthine and, subsequently, to uric acid, by means of the xanthine oxidase enzyme. In most dogs, uric acid is catabolized to allantoin by means of the uricase enzyme. A genetic defect (SLC2A9 mutation) has been described in Dalmatians, which does not allow uric acid to be transported into hepatic cells. It cannot be fully metabolized, even though there are normal levels of uricase enzyme, and in the renal tubules there is less absorption of uric acid, resulting in hyperuricosuria. ${ }^{33}$ In other breeds, possible factors that can influence the formation of these uroliths are purine-rich diets, which can cause high concentrations of uric acid in the plasma, renal excretion, urine concentration, and acidic urinary $\mathrm{pH}$. Dogs with portosystemic shunts have a higher incidence of urate formation, associated with a reduced hepatic conversion of uric acid to allantoin and ammonia to urea, which causes hyperuricemia and hyperammonemia. Dissolution of urate uroliths is usually achieved within four weeks by administering a xanthine oxidase inhibitor, such as allopurinol, and an alkalizing diet restricted in purines, as well as diuretics. ${ }^{33}$ For dogs with a breed predisposition, such as Dalmatians and bulldogs, the recurrence of urolithiasis can be avoided by increasing water consumption, limiting purine intake, and maintaining a $\mathrm{pH} \geq 7$ in the urine, thus promoting urate solubility. In dogs with portosystemic shunts, correction of the vascular anomaly and medical management as mentioned above is recommended. 


\section{Conclusions}

Small breed male dogs, with a median age of six years were the most affected. The most frequent mineral composition of uroliths were struvite and calcium oxalate. However, we observed a high frequency of silicate uroliths, as previously described in Mexico City, unlike populations studied in other geographical areas. Considering the pathophysiological mechanisms of this type of uroliths, a possible geographical component is evidenced, which should be further studied. Additionally, this study provides the tools to make decisions and predictions of urolith composition. This may help to decide between a dietary dissolution therapy or some other type of technique to extract the uroliths, such as urohydropropulsion or surgery. However, all uroliths should be analyzed to know the pathophysiological mechanism involved, in order to select the appropriate medical therapy to avoid their long-term recurrence. 


\section{Funding}

Claudia Iveth Mendoza-López was PhD student, and María Alejandra Aké-Chiñas MSc student with scholarships of the Consejo Nacional de Ciencia y Tecnología (CONACyT) from México.

\section{Acknowledgements}

The authors are grateful to all veterinary doctors in Guadalajara who provided the clinical cases that allowed this study to be done, especially Dr. Carlos Baron de la Mora.

\section{Conflicts of interest}

The authors declare no conflicts of interest in regard to this paper.

\section{Author contributions}

C.I.M.L.: laboratory work, interpreted the results, drafted and wrote the paper; J.D.A.C.: conceived and designed the research, interpreted the results, drafted and wrote the paper; M.A.A.C.: laboratory work; I.A.Q.H.: statistical analysis of the data and paper integration.

\section{References}

1. Lulich JP, Osborne CA, Bartges JW. Canine lower urinary tract disorders. In: Ettinger SJ, Feldman EC. Textbook of veterinary internal medicine-disease of dog and cat. 5th ed. Philadelphia: Saunders; 2000.

2. Mendoza-López Cl, Del Angel-Caraza J, Quijano-Hernández IA, Barbosa-Mireles M. Analysis of lower urinary tract diseases of dogs. Pesq Vet Bras. 2017;37(11):1275-80.

3. Wallerstrom BI, Wagberg TI. Canine urolithiasis in Sweden and Norway: retrospective survey of prevalence and epidemiology. J Small Anim Pract. 1992;33(11):534-39. doi:10.1111/j.1748-5827.1992.tb01047.x.

4. Osborne CA, Lulich JP, Polzin DJ, Sanderson SL, Koehler LA, Ulrich LK, et al. Analysis of 77,000 canine uroliths. Perspectives from the Minnesota Urolith Center. Vet Clin North Am Small Anim Pract. 1999;29(1):17-38. doi:10.1016/ S0195-5616(99)50002-8.

5. Dessombz A, Kirakoya B, Coulibaly G, Ouedraogo RW, Picaut L, Weil R, et al. High prevalence of opaline silica in urinary stones from Burkina Faso. Urology. 2015;86(6):1090-5. doi: 10.1016/j.urology.2015.06.068.

6. Lulich JP, Berent AC, Adams LG, Westropp JL, Bartges JW, Osborne CA. ACVIM Small Animal Consensus Recommendations on the Treatment and Prevention of Uroliths in Dog and Cats. J Vet Intern Med. 2016;30(5):1564-74. doi: 10.1111/jvim. 14559.

7. Wisener LV, Pearl DL, Houston DM, Reid-Smith RJ, Moore AE. Spatial and temporal clustering of calcium oxalate and magnesium ammonium phosphate uroliths in dogs living in Ontario, Canada between 1998 and 2006. Prev Vet Med. 2010;95(1-2):144-51. doi: 10.1016/j.prevetmed.2010.02.016.

8. Ling GV, Thurmond MC, Choi YK, Franti CE, Ruby Al, Johnson DL. Changes in proportion of canine urinary calculi composed of calcium oxalate or struvite in specimens analyzed from 1981 through 2001. J Vet Intern Med. 2003;17(6):817-23._doi: 10.1111/j.1939-1676.2003.tb02520.x. 
9. Barboza MG, Villalobos UA, Mateu L. Evaluación de la composición mineral de los cálculos urinarios que afectan a perros y gatos mediante el uso del análisis cristalográfico por el patrón de difracción de rayos X. Rev Científica FCV-LUZ. 1996;5(1):11-7.

10. Oyafuso MK, Kogikal MM, Waki MF, Prosser CS, Cavalcante CZ, Wirthl VA. Urolitíase em cães: avaliação quantitativa da composição mineral de 156 urólitos. Cienc. Rural. 2010;40(1):102-8. doi: 10.1590/S0103-84782010000100017.

11. Del-Angel-Caraza J, Diez-Prieto I, Pérez-García CC, García-Rodríguez MB. Composition of lower urinary tract stones in canines in Mexico. Urol Res. 2010;38(3):201-4. doi: 10.1007/s00240-009-0248-7.

12. Instituto Nacional de Estadística y Geografía (México). Anuario estadístico y geográfico de Jalisco 2016. Available from: http://internet.contenidos.inegi.org. $\mathrm{mx}$ / contenidos/Productos/prod_serv/contenidos/espanol/bvinegi/productos/ nueva_estruc/anuarios_2016/702825082048.pdf

13. Hidalgo A, Carmona P, Bellanato J, Santos M, García J, Cifuentes L. Análisis de cálculos urinarios por espectroscopía infrarroja y raman. Madrid: Instituto de Óptica Daza de Valdés, CSIC; 1983.

14. Herrera BE. Base de datos de espectros de referencia por espectroscopia infrarroja (FT-IR) de urolitos de silicato y mezclas con otros minerales [tesis de licenciatura]. Toluca: Universidad Autónoma del Estado de México; 2017.

15. Osborne CA, Lulich JP, Polzin DJ, Allen TA, Kruger JM, Bartges JW, et al. Medical dissolution and prevention of canine struvita urolithiasis: Twenty years of experience. Vet Clin North Am Small Anim Pract. 1999;29(1):73-111. doi:10.1016/ S0195-5616(99)50006-5.

16. Blavier A, Sulter A, Bogey A, Novelli K, Billiemaz B. Résultats des analyses par spectrométrie infrarouge de 1131 calculus urinaires canins prélevés de 2007 à 2010, en France. Pract Med Chir Anim Comp. 2012;47(1):7-16. doi: 10.1016 /j.anicom.2011.11.001.

17. Low WW, Uhl MJ, Kass PH, Rubi AL, Westropp JL. Evaluation of trends in urolith composition and characteristics of dogs with urolitiasis 25, 499 cases (1985- 2006). J Am Vet Med Assoc. 2010;236(2):193-200. doi: 10.2460/ javma.236.2.193.

18. Ling GV, Ruby AL, Johnson DL, Thurmond M, Franti CE. Renal calculi in dogs and cats: Prevalence, mineral type, breed, age and gender interrelationships (19811993). J Vet Intern Med. 1998;12(1):11-21. doi:10.1111/j.1939-1676.1998. tb00491.x.

19. Roe K, Pratt A, Lulich J, Osborne C, Syme HM. Analysis of 14,008 uroliths from dogs in the UK over a 10 years period. J Small Anim Pract. 2012;53(11):63440. doi: 10.1111/j.1748-5827.2012.01275.x.

20. Bende B, Kovács KB, Solymosi N, Németh T. Characteristics of urolithiasis in the dog population of hungary from 2001 to 2012. Acta Vet Hung. 2015;63(3):32336. doi: 10.1556/004.2015.030.

21. Vrabelova D, Silvestrini P, Ciudad J, Gimenez JC, Ballesteros M, Puig P, et al. Analysis of 2735 canine uroliths in Spain and Portugal. Retrospective study: 2004-2006. Res Vet Sci. 2011 ;91(2):208-1 1. doi: 10.1016/j.rvsc.2010.12.006.

22. Brandenberger-Schenk F, Rothenanger $E$, Reusch $C E$, Gerber B. Urolithen von Hunden in der Schweiz von 2003 bis 2009. Schweizer Archiv Für Tierheilkunde. 2015;157(1):41-8. doi: 10.17236/sat00003. 
23. Sosnar M, Bulkova T, Ruzicka M. Epidemiology of canine urolithiasis in the Czech Republic from 1997 to 2002. J Small Anim Pract. 2005;46(4):177-84. doi:10.1111/j.1748-5827.2005.tb00308.x.

24. Houston DM, Moore AE. Canine and feline urolithiasis: examination of over 50 000 submissions of the Canadian veterinary urolith centre from 1998 to 2008. Can Vet J. 2009;50(12):1263-8. PMID:20190975.

25. Ling GV, Franti CE, Johnson BA, Ruby AL. Urolithiasis in dogs III: Prevalence of urinary tract infection and interrrelations of infection, age, sex, and mineral composition. Am J Vet Res. 1998;59(5):643-9. PMID:9582970.

26. Bartges J, Moyers T. Evaluation of d,l-methionine and antimicrobial agents for dissolution of spontaneously-occurring infection-induced struvite urocystoliths in dogs. In Proceedings of Am Coll Vet Intern Med Forum, Anaheim CA, 2010;495.

27. Lulich JP, Osborne CA, Thumchai R, Lekcharoensuk C, Ulrich LK, Koehler LA, et al. Epidemiology of canine calcium oxalate uroliths: Identifying risk factors. Vet Clin North Am Small Anim Pract. 1999;29(1):113-22. doi:10.1016/ S0195-5616(99)50007-7.

28. Gnanandarajah JS, Abrahante JE, Lulich JP, Murtaugh MP. Presence of oxalobacter formigenes in the intestinal tract is associated with the absence of calcium oxalate urolith formation in dogs. Urol Res 2012;40(5):467-73. doi: 10.1007/s00240-011-0451-1.

29. Jones BR, Omodo-Eluk AJ, Larkin H, Rogers KD, Sperrin M. Canine uroliths: analysis of uroliths from dogs in Ireland. Irish Vet J. 2001;54(12):629-32.

30. Houston DM, Weese HE, Vanstone NP, Moore AE, Weese JS. Analysis of canine urolith submissions to the Canadian Veterinary Urolith Centre, 1998-2014. Can Vet J. 2017;58(1):45-50. PMID:28042154.

31. Gómez-Tuena A, Orozco-Esquivel M, Ferrari L. Petrogénesis ígnea de la Faja Volcánica Transmexicana. Boletín de la Sociedad Geológica Mexicana. 2005;57(3):227-83. id=94320266003.

32. Bannasch D, Safra N, Young A, Karmi N, Schaible RS, Ling GV. Mutations in the SLC2A9 gene cause hyperuricosuria and hyperuricemia in the dog. PLoS Genet 2008;4(11):e1000246. doi: 10.1371/journal.pgen. 1000246.

33. Bartges JW, Osborne CA, Felice LJ, Koehler LA, Ulrich LK, Chen M, et al. Bioavailability and pharmacokinetics of intravenously and orally administered allopurinol to healthy dogs. Am J Vet Res. 1997;58(5):504-10. PMID:9140559. 